\title{
GATA4 and DCR1 methylation in glioblastomas
}

\author{
Paulina Vaitkiené, Daina Skiriutè, Kęstutis Skauminas and Arimantas Tamašauskas
}

\begin{abstract}
Background: Epigenetic silencing of tumor suppressor genes plays important role in gliomagenesis. Recently, GATA4 and DCR1 were suggested to be a tumor suppressor genes involved in tumorigenesis in various types of human cancers. However, up to now the methylation frequency of GATA4 and DCR1 genes has not been determined in glioblastoma. In this study, we investigated methylation of GATA4 and DCR1 promoters and their association with patient prognosis in glioblastoma.

Methods: Methylation status of GATA4 and DCR1 promoters was investigated by methylation specific PCR in 99 glioblastoma patients. Statistical analyses were conducted to investigate the association between clinical variables and overall survival time.

Results: GATA4 and DCR1 were aberrantly methylated in $23.2 \%$ and $27.6 \%$ of glioblastoma tumors, but not in normal brain. GATA4 promoter hypermethylation showed significant association with patients age $(p=0.027)$. Relationship between genes promoter methylation and glioblastoma patient survival was not determined.

Conclusions: The present work demonstrated that GATA4 and DCR1 promoter hypermethylation is tumor specific event in glioblastoma but they promoter methylation cannot be considered as a prognostic marker of glioblastoma survival.

Virtual Slides: The virtual slide(s) for this article can be found here: http://www.diagnosticpathology.diagnomx.eu/ vs/1381170351801852
\end{abstract}

Keywords: Glioblastoma, Methylation, GATA4, DCR1

\section{Background}

Glioblastoma multiforme (GBM) is the most common and most aggressive malignant primary brain tumor in humans. Despite multimodality treatment, prognosis is poor, with a median survival time of approximately 14 months. Therefore looking for new markers which would help better diagnose and predict the course of glioblastoma is important. Understanding apoptosis in disease conditions is very important as it not only gives insights into the pathogenesis of a disease but may also leave clues on how the disease can be treated [1]. Apoptosis activation can be triggered either by engagement of cell surface "death receptors" or by cellular stress [2]. The proteins of $\mathrm{Bcl}-2$ family are key regulators of the stressinduced apoptotic pathway [2]. Although, much is known about the pathways and mechanisms of apoptosis, but the

\footnotetext{
* Correspondence: p.grigaite@gmail.com Laboratory of Neurooncology and Genetics, Neuroscience Institute, Kaunas Academy of Medicine, Lithuanian University of Health Sciences, Eiveniu str. 4, Kaunas, LT 50009, Lithuania
}

significance of some genes is not fully clear. Our interests have focused on two genes GATA4 and DcR1, which are related to apoptosis. Both of these genes are located on chromosome 8 p region. Despite 8 p being a relatively small chromosome arm, it is one of the most frequently altered genomic regions in human cancer, and is also rich in candidate oncogenes and tumor suppressor genes associated with the development of certain types of cancers [3]. Deletions in this region are observed in glioblastoma [4]. As an alternative to deletion GATA4 and DcR1 promoter methylation may be associated with clinical data of glioblastoma patients. GATA4 is a member of the GATA family of zinc finger transcription factor, which regulates gene transcription by binding to GATA elements. GATA4 serves as a survival factor in cancer cells by regulating the expression of anti-apoptotic Bcl-2 and Bcl-x L [5]. Although GATA4 was expressed in normal brain, loss of GATA4 expression was observed in 57.6\% (94/163) GBM operative samples and it was a negative survival prognostic marker [6]. According to these data was formed 
hypothesis that promoter methylation of GATA4 gene could be survival prognostic marker.

The protein encoded by $D c R 1$ gene is a member of the TNF-receptor superfamily. This receptor is not capable of inducing apoptosis, and is thought to function as an antagonistic receptor that protects cells from TRAILinduced apoptosis. The expression of this gene was detected in many normal tissues but not in most cancer cell lines, which may explain the specific sensitivity of cancer cells to the apoptosis-inducing activity of TRAIL [7]. Methylation of DcR1 gene promoter was determined in $21 \%$ of low grade gliomas [8] suggesting its role in gliomagenesis.

In this study, we evaluated the methylation status of GATA4 and DcR1 promoters in glioblastoma tumor tissue to support the hypothesis that they are inactivated in glioblastomas by promoter hypermethylation and plays a role as tumor suppressor genes in gliomagenesis.

\section{Methods}

\section{Glioblastoma tumor tissue and normal brain}

In total, 99 glioblastoma tumor samples from initial surgery were collected in Neurosurgery clinics of Hospital of Lithuanian University of Health Sciences (Kaunas, Lithuania) through 2003 to 2009 yr. Written patient consent under the approval of ethics committee of Lithuanian University of Health Sciences was obtained for every patient. Data base closure was in November 2010. Glioblastoma Multiforme WHO grade IV (Original SNOMED ID M-94403) diagnoses were established by experienced pathologists according to the World Health Organization (WHO) classification. We included Human brain DNA (Zymo Research, USA) as normal brain control. Glioblastoma samples were stored in liquid nitrogen before DNA extraction. The following clinical data were determined for each patient: age at the time of the operation, gender, tumor multifocality, time of the last followup and patient status. Survival time was collected for all cases and overall survival calculated from the date of the operation to death, or last contact to the live patients.

\section{DNA isolation and bisulfate modification}

Tumor DNA was extracted from 25-40 mg of frozen tissue using ZR Genomic DNA ${ }^{\mathrm{TM}}$ Tissue MiniPrep (Zymo
Research, USA) according to manufactures protocol. The methylation status of GATA4 and DcR1 promoters was determined by bisulfite treatment of DNA. $400 \mathrm{ng}$ DNA was used for bisulfite modification. DNA modification was performed using EZ DNA Methylation Kit (Zymo Research, USA), and all procedures were done according to manufactures protocol. Bisulfite treated DNA was eluted in $40 \mu \mathrm{l}$ distilled water, and stored in $-80^{\circ} \mathrm{C}$ until MS-PCR.

\section{Methylation-specific PCR}

The methylation status of the GATA4 and DcR1 promoters region was determined by methylation-specific PCR. Primers distinguishing unmethylated $(\mathrm{U})$ and methylated (M) alleles were taken from articles $[9,10]$ are shown as follows in Table 1.

Each PCR reaction contained $20 \mathrm{ng}$ of sodium bisulphite-modified DNA. MSP reaction was performed in $20 \mu \mathrm{l}$ of total volume, using $10 \mu \mathrm{l} \mathrm{Maxima}{ }^{\circledR}$ Hot Start PCR Master Mix (Thermo fisher Scientific, USA) with Hot start Taq DNA polymerase and 10pmol of each primer (Metabion International AG, Germany). Cycling conditions were initial denaturation at $95^{\circ} \mathrm{C}$ for $5 \mathrm{~min}$, 38 cycles of $94^{\circ} \mathrm{C}$ for $30 \mathrm{~s}, 60 / 62^{\circ} \mathrm{C}$ for $1 \mathrm{~min}$ and $72^{\circ} \mathrm{C}$ for $1 \mathrm{~min}$ and final step at $72^{\circ} \mathrm{C}$ for $5 \mathrm{~min}$. For each set of methylation specific PCR reactions human blood lymphocyte DNA treated with bisulfite served as a unmethylated DNA control and as positive methylation control was used 'Bisulfite Converted Universal Methylated Human DNA Standard' (Zymo Research, USA). A water blank control was also included. PCR products were separated on $2 \%$ agarose gels with ethidium bromide and visualized under UV illumination. PCR analyses were repeated.

\section{Statistical analysis}

SPSS Statistics 19 (SPSS Inc., Chicago, IL) software package was used for statistical analysis. The quantitative data presented as median and to show the reliability of the estimate, the confidence interval (CI) with $95 \%$ confidence level was presented. Association between gene methylation data and clinical features of glioblastoma patients were evaluated by using Fisher exact test. To estimate survival functions Kaplan-Meier method was used. For comparing survival time distribution between

Table 1 Primers for MSP

\begin{tabular}{|c|c|c|c|}
\hline Gene & Forward primer $5^{\prime}-3^{\prime}$ & Reverse primer $5^{\prime}-3^{\prime}$ & $\mathrm{Tm},{ }^{\circ} \mathrm{C}$ \\
\hline GATA4-M & GTATAGTITCGTAGTTTGCGTTTAGC & AACTCGCGACTCGAATCCCCG & 62 \\
\hline GATA4-U & TITGTATAGTTITGTAGTTTGTGTTIAGT & CCСAACTCACAACTCAAATCCCCA & 62 \\
\hline DCR1-M & TTACGCGTACGAATTTAGTTAAC & TCAACGACCGACCGAAACG & 60 \\
\hline$D C R T-U$ & GAATTITITATGTGTATGAATTTAGTTAAT & CCATCAAACAACCAAAACA & 60 \\
\hline
\end{tabular}

$\mathrm{M}$ - methylated, $\mathrm{U}$ - unmethylated, $\mathrm{Tm}$ - melting temperature. 
groups the log-rank test was used. A $p<0.05$ was considered significant.

\section{Results}

\section{Characteristics of glioblastoma patients}

The median age at diagnosis was 61.0 yr. (CI: 57.3-64.7). The male to female ratio was: 1:1.3. The median age of males $(\mathrm{n}=42)$ was 58.0 yr. (CI: 52.1-63.9) and females $(\mathrm{n}=57) 61.0$ yr. (CI: 56.9-65.1). Median survival time of glioblastoma patients $(\mathrm{n}=99)$ was 8.9 months (CI: 6.910.8). Most of glioblastoma patients (64\%) survived less than 12 months after operation.

\section{GATA4 and DCR1 promoters are methylated in glioblastoma}

The methylation status of the GATA4 and DcR1 promoter in glioblastoma samples was detected by methylationspecific PCR assay. We evaluated methylation status of the GATA4 promoter in 95 glioblastoma tumors. Promoter hypermethylation was detected in $23.2 \%$ (22/95) of the glioblastoma but not in normal brain. Representative samples are shown in Figure 1. The same studies were performed with $D c R 1$ gene promoter in 98 glioblastoma samples. DcR1 gene promoter hypermethylation was detected in $27.6 \%$ (27/98) of the glioblastoma tumors but not in normal brain.

The detection of bands with both primer sets were found in some but not all of the glioblastoma samples likely because of the existence of non-malignant cells in a fraction of the samples or that only one allele of the gene is methylated.

Among 22 GATA4-methylated cases, five patients (23\%) were younger than 60 years and 17 individuals (77\%) were older than 60 years. There is significant difference in gene methylation ratio between age groups (Fisher's Exact test 2-sided, $p=0.027$; Table 2) and this

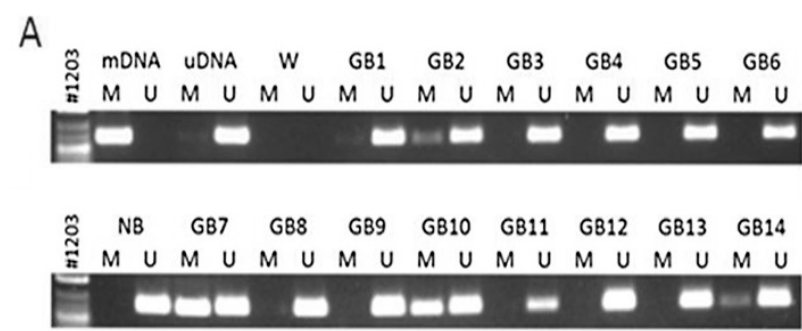

B

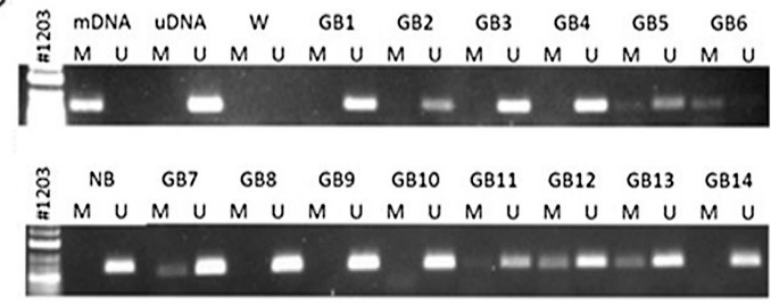

C

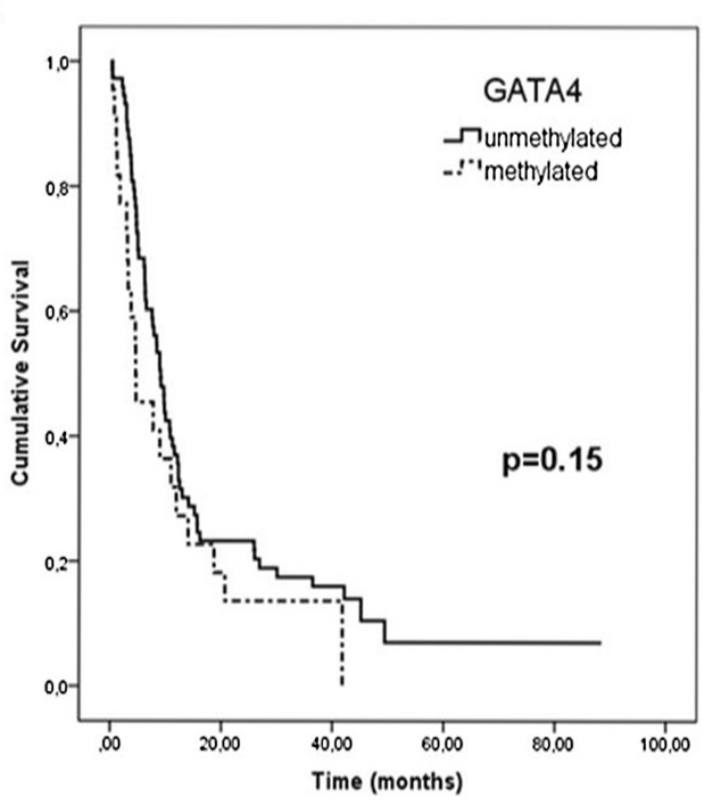

D

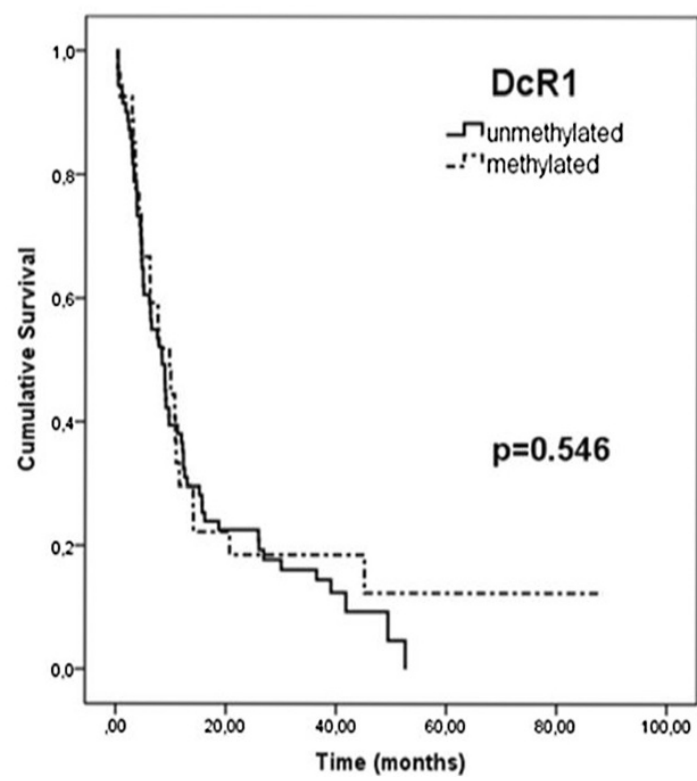

Figure 1 Analysis of GATA4 and DcR1 in glioblastoma; Analysis of GATA4 (A) and DcR1 (B) CpG island promoter methylation status in glioblastoma by the methylation-specific PCR assay. Molecular weight markers are shown in the left, mDNA- methylated DNA control, uDNAunmethylated DNA control, W- water control, GB1-GB14 glioblastoma tumor samples, NB normal brain sample. The presence of visible PCR products in those lanes marked " $U$ " indicates the presence of unmethylated allele genes and " $M$ " indicates the presence of methylated genes. Kaplan-Meier cumulative survival (months) in glioblastoma patients according to methylation status of (C) GATA4 (log-rank test, $p=0.15)$ and (D) DCR1 (log-rank test, $p=0.546$ ). 
Table 2 GATA4 and DCR1 promoter methylation in human glioblastoma tissue with different clinicopathological features

\begin{tabular}{|c|c|c|c|c|c|c|}
\hline \multirow[t]{2}{*}{ Variables } & \multicolumn{2}{|c|}{ GATA4 } & \multirow{2}{*}{$\begin{array}{c}\text { Statistic } \\
\text { significance }\end{array}$} & \multicolumn{2}{|c|}{ DcR1 } & \multirow{2}{*}{$\begin{array}{c}\text { Statistic } \\
\text { significance }\end{array}$} \\
\hline & Methylated & Unmethylated & & Methylated & Unmethylated & \\
\hline Overall & 22 & 73 & & 27 & 71 & \\
\hline Age (years) & & & 0.027 & & & 1.000 \\
\hline$<60$ years & 5 & 37 & & 12 & 32 & \\
\hline$\geq 60$ years & 17 & 36 & & 15 & 39 & \\
\hline Gender & & & 0.473 & & & 0.263 \\
\hline Male & 11 & 30 & & 9 & 33 & \\
\hline Female & 11 & 43 & & 18 & 38 & \\
\hline Multifocal & & & 1.000 & & & 0.185 \\
\hline Yes & 2 & 5 & & 0 & 7 & \\
\hline No & 20 & 68 & & 27 & 64 & \\
\hline Survival (months) & & & 0.227 & & & 1.000 \\
\hline$<24$ & 20 & 57 & & 22 & 57 & \\
\hline$\geq 24$ & 2 & 16 & & 5 & 14 & \\
\hline$D C R 1$ & & & 0.185 & & & - \\
\hline Methylated & 9 & 18 & & - & - & \\
\hline Unmethylated & 13 & 53 & & & & \\
\hline
\end{tabular}

means that GATA4 methylation is related to age. Meanwhile, the interface between the $D c R 1$ promoter methylation status and age is unspecified. No dependences were found between GATA4 and DcR1 promoter methylation and two-year survival time. These genes promoter methylation was not significantly associated with gender or tumor multifocality too (Table 2). In no one of multifocal glioblastomas DcR1 promoter methylation was observed. Maybe the study of a large number of samples could show that DcR1 is an important marker. We analyzed GATA4 and DcR1 promoter methylation for prognostic value of overall survival (OS) using Kaplan-Meier Curves ( $p$ values were generated using the log-rank test) (Figure 1C, D). Analysis showed no association between GATA4 and DcR1 gene promoter methylation and survival in glioblastomas.

\section{Discussion}

Understanding of the molecular alterations that occur during tumorigenesis, and identification of novel markers for cancer diagnosis and novel targets for treatment, may be important for the improvements in tumor diagnosis, treatment and prevention [11]. The most common molecular alterations, that characterize glioblastomas and could be used in current clinical practice and therapeutic decision making, are proliferation markers (Ki67/MIB-1 and phospho-histone-H3 (РHH3)), mutations involving isocitrate dehydrogenase (IDH1 and IDH2) and TP53, also 1p/19q deletion, mutations of Epidermal growth factor receptor (EGFR), O-6-methylguanine-DNA methyltransferase (MGMT) promoter methylation status and glioma-CpG island methylator phenotype [12-14]. Despite extensive efforts at defining biological markers, therapeutic progress for glioblastoma is slow. A further understanding of glioma biology, in concert with welldesigned clinical trials, is necessary to identify more putative molecular biomarkers and unravel the mysteries in the pathogenic mechanisms that trigger this menacing disease [12]. The identification of methylated genes in cancer may provide an insight in the molecular mechanisms of tumor development and might reveal new tools to define markers of prognostic significance [15]. In order to identify molecular markers relevant to glioblastoma development, diagnosis and prognosis promoter methylation analysis of 2 genes, $D c R 1$ and GATA4, was performed.

Loss of GATA4 expression due to promoter hypermethylation has been reported in primary colorectal, gastric, esophageal, lung and ovarian cancer $[10,16]$. To analyze the potential of GATA4 as methylation marker in glioblastoma, we analyzed large series of glioblastoma tumor samples and one normal brain tissue. Were showed that methylation of GATA4 (23.2\%) occurs not at so high frequencies in glioblastoma as in colorectal cancer (70\%) [10] or sporadic gastric carcinomas (53.8\%) [10]. Loss of GATA4 was observed in about $57.7 \%$ GBM operative samples [6]. In our study GATA4 methylation was detected only in $23.2 \%$ of cases, and this may suggest that the GATA4 expression is regulated by different mechanisms or mutation. This could explain the lack of links between GATA4 promoter methylation and survival 
$(\mathrm{p}=0.15)$ in our study contrary to results obtained in Agnihotri et al. (2011) expression studies [6].

A tumor necrosis factor receptor or death receptor family members were found frequently methylated in glioblastoma: TNFRSF10D promoter methylated in 100\% [8], and TNFRSF10A in 68\% [11] of glioblastomas. Methylation of DcR1 gene promoter was determined in $21 \%$ of low grade gliomas (LGGs; World Health Organization [WHO] grade II) [8]. There is not much data about DcR1 promoter methylation in glioblastoma. Martinez et al. (2007) in 16 glioblastoma patients did not found methylation of DcR1 promoter [17]. We have assumed that in glioblastomas this percentage should be much higher. Our research has established that methylation of $D c R 1$ was in $27.6 \%$ of glioblastoma samples, but not in the normal brain DNA, which implied that epigenetic silencing of the DcR1 might be involved in gliomagenesis. This number is close to $37 \%$ in lung cancer cell lines or $30.7 \%$ in ovarian tumors and is very different from $78.0 \%$ methylation in prostate cancer [18-20]. These findings suggest that the prognostic value of promoter hypermethylation of $D c R 1$ could be tissue-specific. The study of gene methylation impact on survival found that the methylation is not associated with survival $(\mathrm{p}=0.54)$. Although promoter hypermethylation of GATA4 and DcR1 genes were found in glioblastoma, they were not associated with patient sex or tumor multifocality in our series. Meanwhile, it was found that GATA4 methylation is related to age $(\mathrm{p}=0.027)$.

\section{Conclusion}

In conclusion, the present work demonstrated that GATA4 and DcR1 promoter hypermethylation is tumor specific event in glioblastoma but they promoter methylation cannot be considered as a prognostic marker in glioblastoma.

\section{Competing interests}

The authors declare that they have no competing interests.

\section{Authors' contributions}

PV did all gene methylation analysis, generated the main idea of the article, did all statistical analysis and wrote the manuscript. DS did DNA extraction and DNA bisulfite modification and contributed to statistical analysis. KS and AT gathered patient tumor sample and clinical data, supervised the project. All authors read and approved the article.

\section{Acknowledgements}

This research was funded by a grant (No. LIG-17/2010) from the Research Council of Lithuania and from the Science Foundation of Lithuanian

University of Health Sciences.

Received: 19 September 2012 Accepted: 30 November 2012 Published: 15 January 2013

\section{References}

1. Wong R: Apoptosis in cancer: from pathogenesis to treatment. J Exp Clin Cancer Res 2011, 26:30-80.

2. Aries A, Paradis P, Lefebvre C, Schwartz RJ, Nemer M: Essential role of GATA-4 in cell survival and drug-induced cardiotoxicity. Proc Natl Acad Sci U S A 2004, 101(18):6975-6980.
3. Tabarés-Seisdedos R, Rubenstein JL: Chromosome $8 p$ as a potential hub for developmental neuropsychiatric disorders: implications forschizophrenia, autism and cancer. Mol Psychiatry 2009, 14(6):563-589.

4. Wemmert S, Ketter R, Rahnenführer J, Beerenwinkel N, Strowitzki M, Feiden W, Hartmann C, Lengauer T, Stockhammer F, Zang KD, Meese E, Steudel WI, von Deimling A, Urbschat S: Patients with high grade gliomas harboring deletions of chromosomes $9 p$ and $10 q$ benefit fromtemozolomide treatment. Neoplasia 2005, 7(10):883-893.

5. Suzuki YJ: Cell signaling pathways for the regulation of GATA4 transcription factor: implications for cell growth and apoptosis. Cell Signal 2011, 23(7):1094-1099.

6. Agnihotri S, Wolf A, Munoz DM, Smith CJ, Gajadhar A, Restrepo A, Clarke ID, Fuller GN, Kesari S, Dirks PB, McGlade CJ, Stanford WL, Aldape K, Mischel PS, Hawkins C, Guha A, Louwagie J, van Criekinge W, Carvalho B, Meijer GA, Baylin SB, Herman JG, de Bruïne AP, van Engeland M: A GATA4-regulated tumor suppressor network represses formation of malignant human astrocytomas. J Exp Med 2011, 208(4):689-702.

7. NCBI. http://www.ncbi.nlm.nih.gov/gene/8794.

8. Laffaire J, Everhard S, Idbaih A, Crinière E, Marie Y, de Reyniès A, Schiappa R, Mokhtari K, Hoang-Xuan K, Sanson M, Delattre JY, Thillet J, Ducray F: Methylation profiling identifies 2 groups of gliomas according to their tumorigenesis. Neuro Oncol 2011, 13(1):84-98.

9. Suzuki M, Shigematsu H, Shivapurkar N, Reddy J, Miyajima K, Takahashi T, Gazdar AF, Frenkel EP: Methylation of apoptosis related genes in the pathogenesis and prognosis of prostate cancer. Cancer Lett 2006, 242(2):222-230.

10. Wen XZ, Akiyama Y, Pan KF, Liu ZJ, Lu ZM, Zhou J, Gu LK, Dong CX, Zhu BD, Ji JF, You WC, Deng DJ: Methylation of GATA-4 and GATA-5 and development of sporadic gastric carcinomas. World I Gastroenterol 2010, 16(10):1201-1208.

11. Wang Q, Deng J, Yuan J, Wang L, Zhao Z, He S, Zhang Y, Tu Y: Oncogenic reg IV is a novel prognostic marker for glioma patient survival. Diagn Pathol 2012, 7(1):69.

12. Olar A, Aldape KD: Biomarkers classification and therapeutic decisionmaking for malignant gliomas. Curr Treat Options Oncol 2012, 13(4):417-436

13. Weller M, Stupp R, Hegi M, Wick W: Individualized targeted therapy for glioblastoma: fact or fiction? Cancer J 2012, 18(1):40-44.

14. Gömöri E, Pál J, Kovács B, Dóczi T: Concurrent hypermethylation of DNMT1, MGMT and EGFR genes in progression of gliomas. Diagn Pathol 2012, 20:7-8.

15. Poplawski T, Tomaszewska K, Galicki M, Morawiec Z, Blasiak J: Promoter methylation of cancer-related genes in gastric carcinoma. Exp Oncol 2008, 30:112-116.

16. Hellebrekers DM, Lentyes MH, van den Bosch SM, Melotte V, Wouters KA, Daenen KL, Smits KM, Akiyama Y, Yuasa Y, Sanduleanu S, Khalid-de Bakker CA, Jonkers D, Weijenberg MP, Louwagie J, van Criekinge W, Carvalho B, Meijer GA, Baylin SB, Herman JG, de Bruine AP, van Engeland M: GATA4 and GATA5 are potential tumor suppressors and biomarkers in colorectal cancer. Clin Cancer Res 2009, 15(12):3990-3997.

17. Martinez R, Setien F, Voelter C, Casado S, Quesada MP, Schackert G, Esteller M: $\mathrm{CpG}$ island promoter hypermethylation of the pro-apoptotic gene caspase8 is a common hallmark of relapsed glioblastoma multiforme. Carcinogenesis 2007, 28(6):1264-1268.

18. Shivapurkar N, Toyooka S, Toyooka KO, Reddy J, Miyajima K, Suzuki M, Shigematsu H, Takahashi T, Parikh G, Pass HI, Chaudhary PM, Gazdar AF: Aberrant methylation of trail decoy receptor genes is frequent in multiple tumor types. Int J Cancer 2004, 109(6):1264-1268.

19. Teodoridis JM, Hall J, Marsh S, Kannall HD, Smyth C, Curto J, Siddiqui N, Gabra H, McLeod HL, Strathdee G, Brown R: CpG island methylation of DNA damage response genes in advanced ovarian cancer. Cancer Res 2005, 65(19):8961-8967.

20. Cheng Y, Kim JW, Liu W, Dunn TA, Luo J, Loza MJ, Kim ST, Zheng SL, Xu J, Isaacs WB, Chang BL: Genetic and epigenetic inactivation of TNFRSF10C in human prostate cancer. Prostate 2009, 69(3):327-335.

doi:10.1186/1746-1596-8-7

Cite this article as: Vaitkiene et al:: GATA4 and DcR1 methylation in glioblastomas. Diagnostic Pathology 2013 8:7. 